\title{
LEPROSY POLICY IN UGANDA
}

\author{
James A. Kinnear Brown, M.D., B.Sc., M.R.C.S., D.T.M.
}

East Africa has always had a place of interest in the news but in recent months it has been unusually and unhappily prominent. In leprosy circles attention has also been focussed on East Africa, of which Uganda is a part, and it may therefore be useful to give my impressions after -12 months of fairly concentrated investigation.

Uganda lies with its southern border on the equator and embracing the northern shores of Lake Victoria. It stretches northwards to the Sudan, westwards to the Belgian Congo, and eastwards to the highlands of Kenya. It has an area of 93,000 square miles, is roughly in the shape of a square and is an undulating plateau some 4,000 feet above sea level. Rather more than one seventh of its surface is swamp or open water. Its climate is tropical but pleasant, the heat of mid-day being relieved by the comparative coolness of the evening and early forenoon. Its people are a heterogenous collection of Bantu, Hamitic and Nilotic origin and whilst the main tribes can be located geographically in well defined areas, the exact pattern is somewhat irregular, reflecting as it does the history of various migrations and the effect of the general labour pattern in the Protectorate. The population is almost the equivalent of that in Kenya, and includes some 5 million Africans, about 50,000 Asians and approximately 5,000 Europeans, the latter being mostly in Government, commerce or mission employment. The municipality of Kampala and townships such as Jinja and Mbale are modern developments indicating industrial and trading concentrations, rather than the natural residential locations of a people with urban habits. The inhabitants are dispersed fairly evenly over the countryside, each family to its plot of land; a picture more rural than England in the days of the stage coach. There are neither villages nor towns but rural parishes and rural boroughs, and these factors, which are of the utmost importance in their influence on every phase of development, must be remembered over and over again when trying to assess and understand East African problems from a distance.

The incidence of leprosy in Uganda has been reasonably estimated by Ross Innes at 80,000 with an overall average of $I \cdot 7 \%$. The distribution however has not yet been determined, and because it may help towards an understanding of the epidemiology of the disease, extensive efforts have been made or planned during $195^{2}$ to define the incidence in different areas. Impressions of the prevalence of the disease based on those attending for treatment might 
give indications, but they can be quite misleading. In one unit of 2,000 people, occupying an area of ten square miles, I9 cases were known to have gone to a settlement many miles away. As proportionately so many had travelled the long distance from this one parish, it would not have been unnatural to imagine that this pointed to an unusually high incidence . In actual fact, a survey revealed only a similar number who had not made the journey, and only three cases that had not been recognised by the chiefs, a total incidence in the parish of $2 \%$, or little more than the general average. Elsewhere there had been some pressure for a new settlement because of the heavy local prevalence but a preliminary survey did not disclose anything more than the average; whereas 25 miles away where there had been little apparent anxiety, a survey revealed an incidence of $5 \%$, the highest figure yet obtained. Much depends on the appreciation of the value of treatment or the degree to which public opinion is leprosy conscious. Such influences may invalidate attempts made to determine the incidence by examining large numbers of people collected at a hospital, dispensary or other convenient place, because if the people are concerned to have their own treatment centre, patients may be summoned from far and near to create an impression; whereas if it does not pay to become recognised only those will attend who are certain they are beyond suspicion.

Similarly in assessing the results of surveys great care has to be taken; as for example in one survey producing the unexpected result of $6 \%$ it was found that the area was a place of resettlement after sleeping sickness measures, and being within three miles of a settlement, all the cases were out-patients who had squatted and none were actually native to the locality. In another instance the $3 \%$ was made up half of immigrants from other tribes and half of the local populace.

Much of the years' work, as far as surveys are concerned has been spent in developing a technique whereby 100\% of representative units, that is, natural parishes that can always be identified and examined again, can be examined in privacy under the best conditions. The dispersal of the population makes it quite impossible even to think of house to house visitation, but it is satisfactory that now in almost every survey it is possible to account for practically every member of the community if not at the first visit, certainly at the follow up, some days or weeks later.

It will take some time to complete the picture for the timing of the surveys depends on many factors, among which may be mentioned the weather, planting and harvesting, and other district activities, and to secure results which everyone will feel satisfied contain as little margin of error as possible, one has to be content 
to make haste slowly. Explanations at every point are essential to gain the confidence that is a necessary prerequisite; this itself takes time, time that is well spent, and it may be remarked that the cooperation of the administrative and medical officers has been willingly and unsparingly given.

During 1952 upwards of thirty surveys have been attempted by different methods throughout the country, and whilst some have been preliminary or experimental, others have given results which are felt to be beyond serious doubt. Figures have been obtained as low as $0.4 \%$ some around $\mathrm{r} \%$, and a few with values of $2 \%$, $3 \%$ and one of $5 \%$. It must be understood that these figures refer not to massive districts but to discreet parishes, occupying areas of perhaps four to ten square miles and with populations of between five and fifteen hundred. Having concentrated deliberately on areas of reputedly high incidence, it is hardly likely that in other similar sized units, in the same districts, any higher figures will be obtained; what may eventuate in districts where work has not yet been atttempted it is not wise to speculate. Side by side, where the chiefs appeared to be quite reasonably accurate with their diagnosis, attempts have been made to appoint African inspectors to the task of examining and visiting every known or suspicious case in much larger units, for checking on some convenient occasion, in order more rapidly to obtain a picture of conditions over wider areas, and to decide whether the figures obtained for the smaller parishes do in fact reflect the general situation.

Apart from the statistical evidence which has been obtained, much time has been spent in conferring both before and after the surveys with the official representatives of the people to explain what has been found and what may be necessary to introduce treatment into the district. These have been very happy occasions, when much of value has been learnt as well as taught, and simply by behaving as good listeners, inferences have been confirmed about the fluctuations of the disease. So far it may be said that there appears to be reasonable evidence that in some areas the disease may be spontaneously dying out, whilst in others the disease constitutes a problem needing greater concentration. There is a general desire to bring the disease under complete control, a desire which is growing as treatment centres are opened and as the scope of the surveys increases. The final statistical picture will take a long time to complete, but the surveys have a more immediately practical value in that they are not only a means of contact and of obtaining confidence in relation to what it is proposed to introduce, but the best method of determining the most tactical points at which to make the introduction. It is as important to establish facilities 
where there are the greater concentrations of disease as to avoid being persuaded by any kind of vociferous clamour to dissipate the limited resources where the incidence hardly requires anything very ambitious.

How is the problem to be met? To put all the cases in leprosaria would be counsel of perfection which is quite impossible on the grounds of expense and of the skilled personnel required. To limit the use of leprosaria to lepromatous cases and to children would be an admirable middle course, but this unfortunately is still outside the bounds of what is economically practicable, and such a course would still leave out of account a large number of patients who might need hospitalisation during their treatment. The presence of a number of the more able bodied tuberculoid patients in properly organised leprosaria helps to a greater degree of seltsupport and therefore to extending the work of the settlement with the same income to a greater number of patients. The limiting factors are economic, and to recognise them and plan accordingly is not to be casual but realistic. If leprosy were the only endemic disease it would not be so necessary to talk about such limitations, but there are unfortunately others which menace the whole population, some in a greater degree, and which threaten the productivity of the people upon which depends the ability to finance the whole of the medical, educational and social programme. It was a consideration of such factors and that the accommodation of the favoured few would not lead to any regression of the disease in the country that led the writer in 1936 after pioneering and organising the Uzuakoli settlement in Southern Nigeria to look beyond settlements for the final answer, and to publish the principles of control that were later adopted. In Uganda the problem is similar, though conditions are different, and whilst its solution will hinge on the effective use of settlements, the problem in the field will require a somewhat modified orientation. From a humanitarian point of view one patient restored to health is an achievement of which one can be justly proud, but what is even more humanitarian is the spreading of all the resources of manpower and money so that the healthy are nowhere at risk and all who need it have treatment available to them. These are the principles actuating present policy by which any other considerations however admirable in themselves, are quite secondary.

Village segregation and village clinics are impossible because as has been stated villages do not exist. The dispersal of the people which may have its own value in restricting the spread of infectious disease, increases the difficulty in applying communal public health measures. To expect patients to travel ten or twenty miles once $\mathrm{o}_{\mathrm{i}}$ 
twice a week for months or years is quite unrealistic and to entrust them with a month's supply of tablets is definitely unsafe except perhaps in a very few isolated instances. Segregation in some form secures the rest of the population and makes continuity in treatment a possibility, but segregation must not be imposed from above, so much as induced from below. For this reason the various councils with the African leaders are of value in explaining how partial yet not inconvenient segregation will lessen the danger and make treatment possible through the ordinary medical channels. Posters illustrating the effect on parishes accepting or neglecting this first step are being prepared and it is hoped they will be shortly in wide circulation.

A rigid plan of action which might be applied to the whole of Uganda is unlikely to be fully effective. Even in a country as small as this there are many variations of a tribal and environmental nature and the result of these would be that an inflexible programme would be effective only where it happened to fit. The following are the broad principles which it is considered will allow of the necessary elasticity in application:

(a) The use of the existing settlements insofar as they are geographically convenient, as Primary Residential Centres, to serve as focal points from which will radiate area schemes and to act as training centres for African personnel; together with the establishment of new ones if such are found to be essential. It is hoped that the'se centres, under a qualified staff, will be able to carry out reliable therapeutic trials and routine histopathological investigations. It is equally hoped that in the course of time their own agricultural development will enable them to support a larger number of patients.

(b) The development of secondary residential centres, staffed by ex-patients and supervised by the Government medical officer with the assistance of the District Commissioner, and the Agricultural and Forestry Officers. Three of these have been begun during the year. They are financed entirely by the local governments, and have a resident chief appointed and salaried by the local government. A fourth has been accepted by the African authority in another district. They are experimental but the early stages of their development have been most encouraging. Whether a European in charge will be essential if they grow beyond their present capacity remains to be seen. So far they are a credit to the officers sponsoring them.

(c) The three centres thus established are on a district basis, 
a district being analogous to one of the larger counties in Great Britain. There may be centres for smaller areas, areas which at home would be described as rural parish or borough centres. The principle of these will be that the patients (with their families if necessary) will settle in one part of the area near a dispensary outpost. In other words, this means organised and controlled squatting; but where the family moves, the patient if infectious will need to observe night segregation.

(d) The creation of treatment facilities at existing dispensaries or at specially provided outposts, where owing to land tenure, or for any other reason organised segregation is impracticable.

At every stage the advice of the responsible chiefs is being encouraged as it will be to them that one will have to look for the full implementation of the details. It is a flexible scheme and the wheels will revolve slowly in the beginning, but it is hoped they will gather momentum as experience is gained.

Leprosy work in Uganda, as in most of the Dependencies, has been hitherto very much the responsibility of the missionary societies extensively aided by the Protectorate government, the British Empire Leprosy Relief Association and philanthropically disposed individuals. The capacity of outside organisations to shoulder any more of the burden, however, is becoming severely limited by the various changes which have taken place in the external social structure. Equally the order within the colonies and protectorates has undergone vast evolutionary changes, and whilst Governments have always been anxious to reinforce as much as possible every effort by indigenous populations towards selfhelp, it is now becoming increasingly necessary as development proceeds to stimulate the people more and more to rely on the fruits of that development for the relief of their own social problems. In this respect the outlook in Uganda is distinctly encouraging and it is gratifying to see indications that the people will be able to appreciate this policy; it is only on this appreciaton and with the salutory discipline of self-help that the vital factor of maintenance may be safeguarded for the future.

I need only add that I am grateful to all the administrative and medical officers of the Government of Uganda and to the representatives of the missionary societies and the British Empire Leprosy Relief Association for their interest and assistance, and to the Director of Medical Services for his encouragement and permission to publish this paper. 